
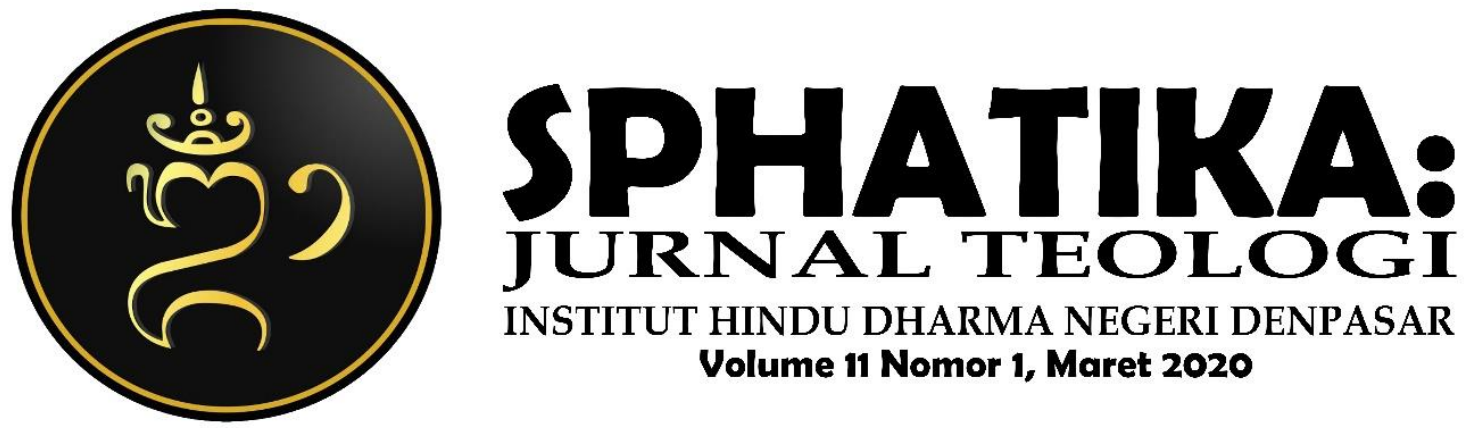

\title{
RUPA GAYAH DALAM RITUAL MASYARAKAT HINDU DI DESA SEMBUNG, MENGWI, BADUNG
}

\author{
I Gde Suryawan \\ I Nyoman Duwika Adiana \\ I Kadek Jayanhti Riva Prathiwi \\ Institut Hindu Dharma Negeri Denpasar
}

\begin{tabular}{|l|l|}
\hline Keywords: & ABSTRACT \\
\hline Rituals & Style is a collection of several satays and the bones of \\
animals slaughtered (usually pigs) and then shaped so that they & look attractive. In general the form of style can be divided into \\
three namely the style of style, body style and peak style. Alas \\
gayah consists of pig bones arranged like pigs while alive. On \\
the body of the style is composed of several satay namely \\
pengideran satay, satay that symbolizes the Gods Nawa Sanga \\
(nine Gods who control the nine cardinal directions), pengurip- \\
urip satay is satay which shows the amount of urip Dewata \\
Nawa Sanga, and satay decoration is satay which symbolizes \\
the contents of the nine directions of the compass; the world and \\
functioning style decoration. The form of style in each region in \\
Bali varies according to the taste of art and creativity of the \\
maker, but has the same symbol and meaning, which is the \\
symbol of the universe and is meaningful as a neutralizing the \\
negative elements of the Great Bhuwana (nature) and Bhuwana \\
Alit (humans).
\end{tabular}

\section{PENDAHULUAN}

Masyarakat Hindu di Bali mengenal banten dalam pelaksanaan upacara. Banten adalah alat bantu, simbol ketulusan dan bhakti ke hadapan Tuhan Yang Maha Esa, yang memiliki bentuk sangat khas dan unik, mengaitkan daya cipta yang religius dan mengandung magis dan budaya seni (Surayin 2002: 5). Adanya mengaruh dari Sapta Rsi (tujuh Rsi), terutama empu Sang Kulputih yang mengajarkan membuat banten berbentuk seni (Sugriwa,1991:3). Salah satu banten yang bentuk unik adalah gayah, menurut pengertiannya, gayah adalah 
kumpulan beberapa jenis sate dan tulang-tulang hewan yang disembelih kemudian disusun sedemikian rupa sehingga berbentuk menyerupai meru (Sudarsana, 2001: 25).

Umat Hindu di Bali juga mengenal konsep desa, kala, patra, yaitu desa adalah tempat dimana kita berada. Jadi dalam membuat banten kita menyesuaikan diri dengan tempat dimana kita berada, baik itu masalah bahan yang digunakan, bentuk dll. Kala adalah waktu, selain tempat membuat banten juga harus memperhatikan waktu, mampu atau tidak kita membuat banten yang sesuai dengan harapan kita, dan yang terakhir patra adalah keadaan, maksudnya dalam membuat banten hendaknya melihat keadaan atau kemampuan, salah satunya adalah kemampuan materi. Adanya konsep Desa, kala, Patra membuat bentuk gayah di setiap daerah di Bali berbeda-beda, namun memiliki makna yang sama. Di Desa Sembung, Kecamatan Mengwi, Kabupaten Badung misalnya, bentuk gayah tidak menyerupai meru pada umumnya.

\section{PEMBAHASAN}

\section{Cara Pembuatan Gayah}

Cara membuat gayah di Desa Sembung, Mengwi, Badung, dapat dikelompokkan menjadi 3 (tiga) yaitu:

(a)

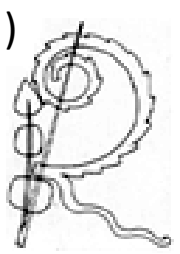

(b)

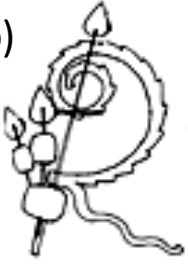

(c)

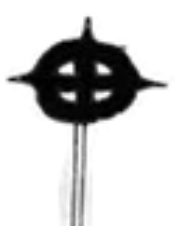

(d)

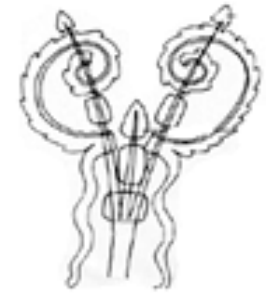

(i)

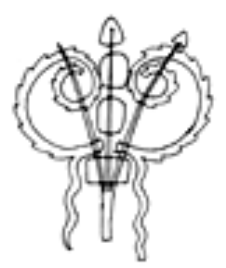

(e)

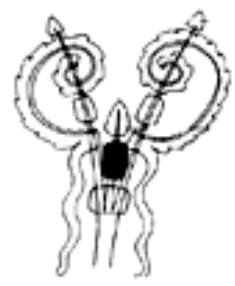

(f)

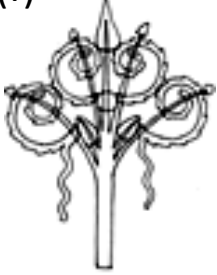

(h)

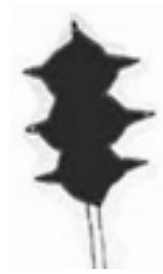

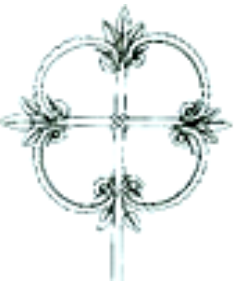

(g)

Gambar: 1 Sate pengideran

Sumber: Duwika

a. Sate pengideran

Sate pengideran adalah sate yang melambangkan senjata Dewata Nawa Sanga (sembilan Dewa yang menguasai arah mata angin), antara lain: (a) sate sepit gunting, lambang trisula senjata Dewa Sambhu sebagai penguasa arah timur laut. (b) sate pipid/suduk ro, lambang angkus senjata Dewa Sangkara penguasa arah barat laut. (c) sate cakra, lambang cakra senjata 
Dewa Wisnu sebagai penguasa arah utara. (d) sate jepit babi, lambang genta atau bajra senjata Dewa Iswara sebagai penguasa arah timur. (e) sate jepit balung, lambang nagapasa senjata Dewa Mahadeawa sebagai penguasa arah barat. (f) sate penyeneng, lambang dupa senjata Dewa Maheswara sebagai penguasa arah tenggara. (g) sate pras, lambang moksala senjata Dewa Rudra sebagai penguasa arah barat daya. (h) sate gada, lambang gada senjata Dewa Brahma sebagai penguasa arah selatan. Dan puncak gayah menggunakan (i) sate kuung bungan duren atau (j) sate bagia/dangsil (sesuai dengan jenis Gayah), lambang padma senjata Dewa Siwa sebagai penguasa arah tengah

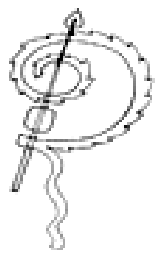

(a)

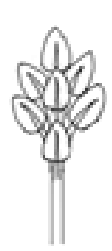

(b)

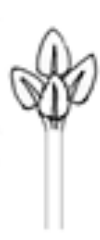

(c)

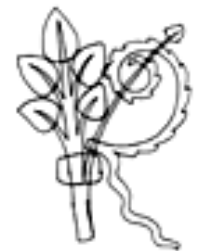

(d)

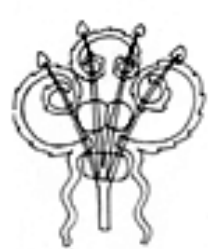

(e)

b. Sate hiasan

\section{Gambar: 2 Sate hiasan}

Sumber: Duwika

Sate hiasan adalah simbol dari isi bumi/alam semesta (Bhuana agung), antara lain: (a) sate kuung tunggal, lambang tumbuhan plawa maknanya kesuburan, sate ancak/bingin, lambang pohon bringin maknanya keagungan, (b) sate cepaka, lambang bunga cepaka yang memiliki makna keindahan, (c) Sate cepun, cepun adalah nama bunga, sate ini memiliki makna keasrian, (d) sate nagasari, lambang plawa yang paling indah, makna dari sate nagasari adalah kemegahan, (e) sate lawangan, lambang Candi bentar maknanya sebagai pintu masuk.

(a)
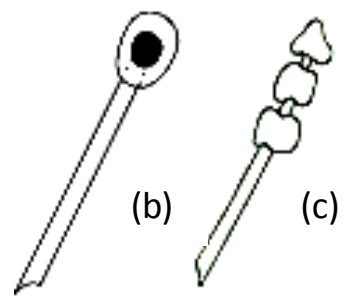

Gambar: 3 Sate pengurip-urip

Sumber: Duwika 
c. Sate pengurip-urip

Sate pengurip-urip berfungsi sebagai penunjuk jumlah urip setiap sate pengideran atau Dewata Nawa Sanga, sate ini juga bisa dipakai sebagai hiasan pada gayah agar kelihatan lebih ramai dan menarik. Sate penguripan itu antara lain, (a) sate kablet, (b) sate asem dan (c) sate lembat, yang memiliki makna penciptaan.

Untuk tempat menancapkan sate, dibuatkan alas gayah yang terdiri dari tulang-tulang babi. Tulang-tulang babi itu kemudian disusun seperti ketika masih hidup, proses menyusun tulang ini disebut dengan bangun urip. Tulang-tulang itu antara lain: kaki/balung batis, tulang kering/balung linggis, tulang paha/balung ketupang, tulang rusuk/balung ige, tulang punggung/balung gegending, tulang hidung dan tengkorak ada pada kepala babi dan ekor. Disamping itu semua organ babi juga digunakan seperti hati, jantung, par u-paru, limpa, dll. Setelah itu, sate-sate tadi ditancapkan pada kepala babi sesuai dengan tempatnya dan ditata sesuai kreatifitas pembuatnya.

\section{Bentuk Gayah di Desa Sembung}

Bentuk Gayah di Desa Sembung, Mengwi, Badung. Sesuai dengan tingkatan upacara (nista, madya, uttama) atau jenis bebangkit yang digunakan, gayah dibagi menjadi 3 (tiga) yaitu:

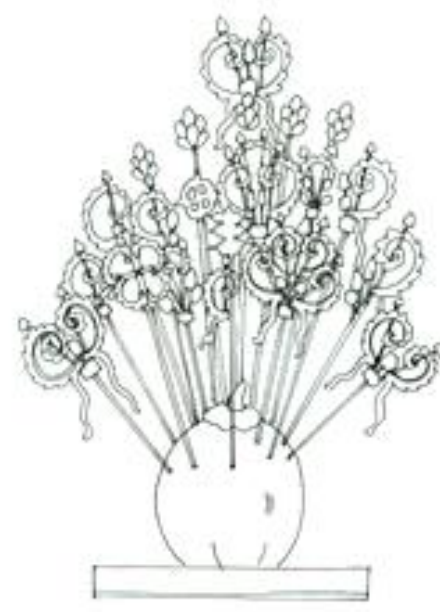

Gambar: 4 Gayah sari

Sumber: Duwika

a. Gayah sari,

Gayah sari yaitu gayah yang bentuknya paling sederhana. Tempat menancapkan sate biasanya menggunakan kelapa. Sate pengideran jumlahnya lengkap yaitu sembilan buah, sate hiasan jumlahnya menyesuaikan tergantung pada rasa seni pembuatnya dan sate 
penguripan cukup diisi satu buah disetiap arah mata angin. Puncak gayah menggunakan sate kuung bungan duren. Gayah ini biasanya digunakan pada upacara yang tingkatannya nista/sederhana atau pada bebangkit gerombong.

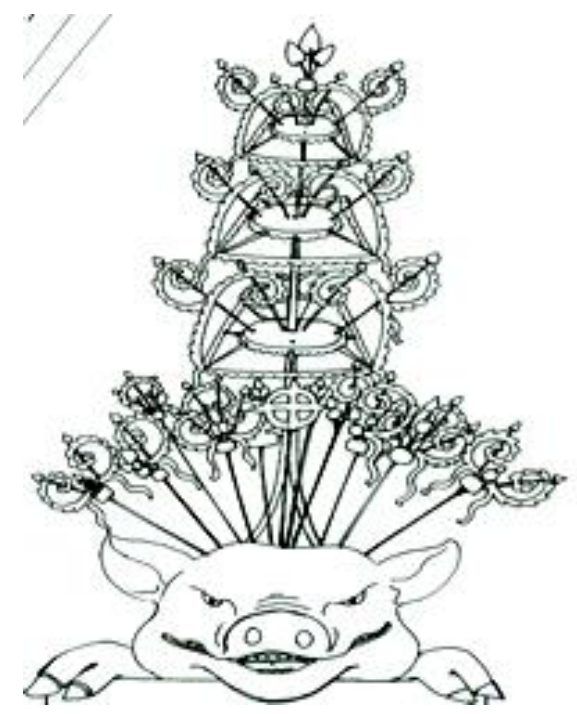

b. Gayah utuh

\section{Gambar: 5 Gayah utuh} Sumber: Duwika

Gayah utuh alasnya menggunakan kepala babi. Jumlah sate pengideran lengkap, sate hiasan yang terdiri dari: sate kuung tunggal, sate bingin, sate jepun, sate cepaka, dan sate nagasari, biasanya dibuat lebih banyak daripada gayah sari agar kelihatan lebih indah dan renteb atau ramai. Sate pengurip-urip yaitu: sate lembat, sate asem dan sate kablet, jumlahnya sesuai dengan masing-masing urip Dewata Nawa sanga (sembilan Dewa yang menguasai sembilan arah mata angin), yaitu Dewa Wisnu di utara uripnya 4, Dewa Sambhu di timur laut uripnya 6, Dewa Iswara timur uripnya 5, Dewa Maheswara di tenggara uripnya 8, Dewa Brahma di selatan uripnya 9, Dewa Rudra di barat daya uripnya 11, Dewa Mahadewa di barat uripnya 7, Dewa Sangkara di barat laut uripnya 3 dan di tengah Dewa Siwa uripnya 8. Untuk puncak gayah utuh menggunakan dangsil yaitu sate bagia yang bertingkat-tingkat. Tingkatan dangsil untuk gayah ini adalah 3-5 tingkat. Gayah ini digunakan pada upacara yang tingkatannya menengah (madya) atau pada bebangkit bogem/mecagak. 


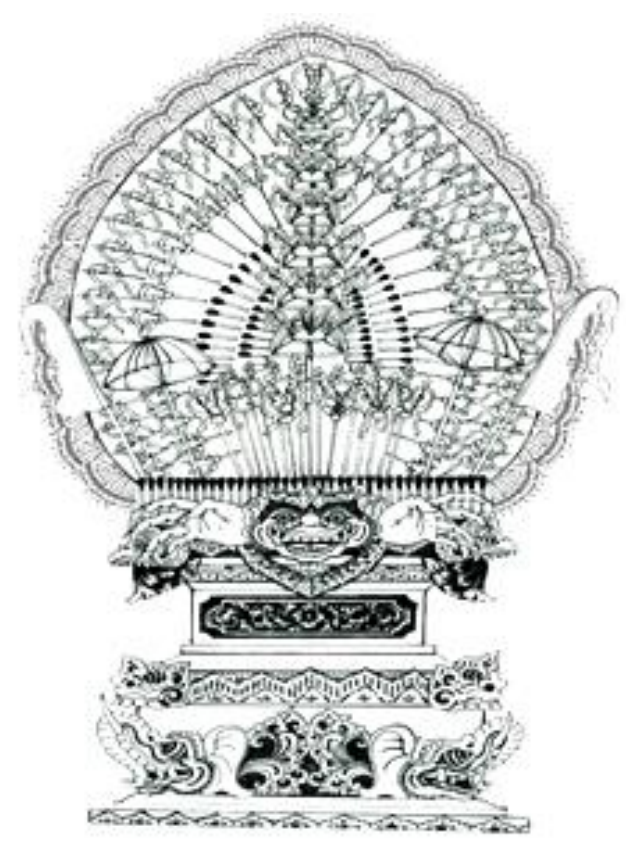

Gambar: 6 Gayah Agung

Sumber: Duwika

c. Gayah agung

Gayah agung cara membuatnya sama seperti gayah utuh. Sate yang digunakan juga sama, yaitu sate pengideran, sate pengurip-urip, dan sate-sate hiasan. Hanya saja gayah agung, sate pengurip-urip tidak menggunakan sate kablet, sate asem atau sate lembat melainkan sate pengideran dibuat sebanyak uripnya masing-masing, yaitu:

a. Sate jepit babi 5 buah/katih di sebelah timur.

b. Sate suduk ro 3 buah/katih di sebelah barat laut

c. Sate pras 11 buah/katih di sebelah barat daya.

d. Sate Cakra 4 buah/katih di sebelah utara.

e. Sate penyeneng 8 buah/katih di sebelah tenggara.

f. Sate Gada 9 buah/katih di sebelah selatan.

g. Sate jepit balung 7 buah/katih di sebelah barat.

h. Sate sepit gunting 6 buah/katih di sebelah timur laut.

i. Sate bagia dengan tumpang/tingkat 7, 9, 11 di Tengah.

Sate-sate diatas ditancapkan pada kepala babi, sedangkan dangsil ditancapkan pada potongan batang pisang. Pada bagian belakang dibuat hiasan yang menyimbolkan alas (hutan) menggunakan sate lembat, sate bingin dan sate kekuung tunggal. Sate-sate ini ditancapkan pada gabus (kalau dulu menggunakan sabut kelapa) dan disusun sedemikian rupa dari sate lembat, sate bingin dan yang terakhir adalah sate kuung tunggal yaitu gayah yang bentukknya paling besar/megah. Gayah ini menggunakan badan bungkur atau alas 
yang bentuknya seperti badan candi atau pura. Badan bungkur ini dihiasi dengan ornamen bali seperti karang boma, karang goak, karang tapel, karang gajah, simbar dll. Sate untuk menunjukkan jumlah urip tidak menggunakan sate lembat, kablet atau asem, tetapi sate pengideran dibuat sejumlah uripnya. Puncak gayah menggunakan dangsil yang bertingkat 7, 9, 11. Gayah ini digunakan pada upacara besar atau tingkat uttama.

\section{Fungsi Gayah}

Gayah memiliki fungsi religius, yaitu gayah merupakan salah satu sarana perlengkapan dalam upacara Hindu di Bali. Gayah ini diterapkan pada Panca Yadnya (Dewa Yadnya, Manusa yadnya, Pitra yadnya, Rsi yadnya, dan Bhuta yadnya). Adapun persyaratan menggunakan gayah adalah pada upacara yang tingkatannya menengah (madya) ke atas atau disebut juga nadi atau nyatur.

Dari konsep di atas maka dapat disimpulkan bahwa gayah digunakan pada upacara panca yadnya seperti :

a. Dewa yadnya, odalan di kahyangan-kahyangan, mapedagingan. Bentuk gayahnya lengkap menggunakan sate pengideran, pengurip-urip dan beberapa sate hiasan. Puncak gayah (sate kuung bungan duren, sate bagia dari 1 tingkat hingga 11 tingkat) disesuai dengan bebangkit yang digunakan (bebangkit-gerombong, gayah yang digunakan adalah gayah sari, bebangkit bogem/mecagak, gayah yang digunakan adalah gayah utuh, bebangkit agung/mekaras, gayah yang digunakan adalah gayah agung). Untuk odalan biasa, gayah diletakkan di ajeng (depan) pelinggih atau piasan/piodalan, untuk odalan nyatur (besar) gayah diletakkan di sor (dibawah) surya, pengubengan (tempat memanggil beliau) dan di piodalan (di piyasan/di tempat banten odalan).

b. Manusa yadnya, biasanya pada upacara memetik, dan perkawinan, gayah yang digunakan adalah gayah sari dan gayah utuh, satenya bisa tidak menggunakan semua sate pengideran, cukup sate hiasan dan sate penguripan. Tempat gayah diletakkan pada sor surya dan ayaban/pengubengan.

c. Pitra yadnya, biasanya upacara pengabenan sawa preteka (pengabenan tingkat utama), menggunakan gayah utuh dengan semua sate pengideran tetepi belum menggunakan dangsil (sate bagia yang bertingkat) puncak gayah cukup menggunakan sate bagia. Gayah ini diletakkan di sor surya, pengubengan dan pekiriman (banten yang menghantarkan roh)

d. Rsi yadnya, biasanya upacara medwi jati, gayah yang digunakan gayah sari atau gayah utuh dengan menggunakan 5 (lima) macam sate pengideran, dan belum menggunakan dangsil. Letak gayah pada sor surya dan di ayaban. 
e. Bhuta yadnya, yaitu pada upacara caru tawur gentuh, caru manca wali karma, caru eka dasa ludra, dll. gayah yang digunakan, gayah sari, gayah utuh, atau gayah agung sesuai dengan bebangkit yang digunakan. Apabila odalan biasa gayah diletakkan di ajeng pelinggih atau piasan/piodalan, untuk odalan nyatur (besar) gayah diletakkan di sor surya, pengubengan dan di piodalan.

\section{Makna Gayah}

Disamping memiliki fungsi yang sama pentingnya dengan sarana upacara lainnya, gayah juga memiliki simbol dan makna. Gayah yang sudah disusun adalah simbol dari alam semesta. Umat Hindu Bali mengenal alam semesta ini terdiri atas tiga tingkatan (Tri Bhuana), yaitu alam paling bawah disebut dengan bhur loka (alam kegelapan) yang dihuni oleh para Bhuta (raksasa). Bhwah loka adalah alam tempat tinggal manusia yang letaknya di tengah, dan alam yang paling atas adalah alam para Dewa yang disebut dengan Shwah loka. Konsep ini pula yang biasa digunakan oleh umat Hindu di Bali dalam kehidupan seharihari, seperti pada pembuatan bangunan yang terdiri dari pondasi (bhur), ruangan (bhwah), dan atap (shwah). Maka, terbentuklah gayah yang terbagi atas tiga bagian yang merupakan simbol Tri Bhuana, yaitu bagian bawah disebut alas gayah, bagian tengah disebut badan gayah dan bagian atas disebut dengan puncak gayah. Pada bagian bawah gayah atau alas gayah adalah simbol bhur loka, pada bagian tengah gayah atau badan gayah tempat beberapa sate yang ditancapkan adalah simbol bhwah loka, dan puncak gayah pada sate yang letaknya ditengah, sate kuung bungan duren, sate bagia atau dangsil adalah simbol shwah loka. Hiasan pada bagian belakang gayah agung yang bentuknya menyerupai kayonan adalah simbol gunung atau isi dunia.

\section{SIMPULAN}

Gayah adalah kumpulan dari berbagai jenis sate dan beberapa bagian hewan yang disembelih (biasanya babi), seperti tulang punggung, tulang rusuk, tulang paha, tulang betis, kaki, organ dalam babi dll. Kemudian disusun/dirangkai sedemikian rupa agar kelihatan menarik. Gayah merupakan pelengkap banten bebangkit (ulam bebangkit) dalam upacara yang tingkatannya menengah ke atas (nadi/nyatur). Bentuk gayah di setiap tempat berbeda sesuai rasa seni dan kreatifitas pembuatnya, namun memiliki simbol dan makna sama yaitu simbol alam semesta dan berfungsi sebagai penetralisir unsure negative Bhuwana Agung (alam) dan Bhuwana Alit (manusia). 


\section{DAFTAR PUSTAKA}

Sudarsana, I G B. 2001. Dharma Caruban. Denpasar: Yayasan Dharma Acarya Percetakan Mandara Sastra.

Surayin, Ida Ayu Putu. 2004. Melangkah ke Arah Persiapan Upacara-upacara_Yadnya. Surabaya: Paramita.

Yuda Triguna, I.B.G. 2003. Estetika Hindu dan Pembangunan Bali. Denpasar: Widya Dharma. 